S Research S Suare

\title{
A New Determination of Pan-Pathogen Antimicrobials
}

Praveen Prathapan ( $\square$ praveen.prathapan@trinity.ox.ac.uk)

University of Oxford

\section{Research Article}

Keywords: antimicrobial, broad-spectrum anti-infective, COVID-19, host-pathogen interaction, panpathogen antimicrobial

Posted Date: July 28th, 2021

DOI: https://doi.org/10.21203/rs.3.rs-700762/v1

License: (c) (i) This work is licensed under a Creative Commons Attribution 4.0 International License. Read Full License 


\section{Abstract}

Drug repositioning studies in recent decades have revealed a growing number of antimicrobials effective at treating infection types tangential to their original antimicrobial classification. Such 'pan-pathogen antimicrobials' (or 'broad-spectrum anti-infectives') have not yet been formally characterised. This review examines historical limitations of the canonical antimicrobial lexicon in light of the contemporary model for infectious disease and propounds a taxonomy that defines antimicrobials according to the hostpathogen interactome, not the pathogen. By doing so, antimicrobials that are effective at treating multiple infection types are highlighted, namely azithromycin, ivermectin, niclosamide, and nitazoxanide.

Recognition of the pan-pathogen nature of these antimicrobials can stimulate a more unified approach to antimicrobial development cognisant of generalised anti-infective mechanisms within the host-pathogen interactome and anticipatory of future pandemics and bioterrorist attacks.

\section{Introduction}

At the close of the 19th century, the work of Louis Pasteur and Robert Koch led to the 'germ theory' of disease, which stated that pathogens, too small to see without magnification, can cause disease ${ }^{1}$. This was reciprocated by Paul Ehrlich's 'magic bullet', which described the need for chemical drugs that target the pathogen without harming the host ${ }^{2}$. The magic bullet hypothesis was successfully realised in the 20th century as antibiotics, antifungals, antiparasitics, and antivirals: therapeutics which treat infectious disease by targeting the disease-causing pathogen ${ }^{3}$.

The success of immunomodulatory therapies in treating infectious diseases highlighted a limitation of the germ theory of disease, which did not consider the contribution of the host in determining disease outcome ${ }^{4}$. Even today, a growing understanding of the immune system has enabled the discovery and development of novel drug targets and approaches for immunomodulatory interventions ${ }^{5}$. More advanced types of immune therapies, such as monoclonal antibodies and cytokines, have already entered clinical use and their application is being increasingly expanded ${ }^{6}$. Moreover, during infection, pathogen properties that are mutable, such as antigenic determinants, replicative rates, and tropism, stimulate immune responses to pathogens, which in turn affects the lifecycle of the pathogen. A more inclusive approach to investigating pathogenesis therefore considers the pathogen and host as complex systems that dynamically affect each other ${ }^{7,8}$. When COVID-19 emerged, there were no suitable antiviral drugs available 9 . Over a year later, the most effective treatments for this viral disease have emerged from unanticipated places: anti-inflammatory drugs such as dexamethasone and even the antiparasitic agent ivermectin ${ }^{10}$.

This therapeutic outcome is congruent with the now-accepted model for infectious disease, the "hostpathogen interactome' model, which recognises the contribution of both the host and pathogen in determining disease outcome; an advancement from germ theory ${ }^{11}$. This review examines how antimicrobial development has concomitantly evolved from pathogen-killing magic bullets to host- 
modulating magic blankets; explores how the discovery of general anti-infective signalling pathways such as STING and MAPK provides a pharmacological targetome for such antimicrobials; and formally identifies two clinically-approved pan-pathogen antimicrobials which underscore a novel paradigm of drug development cognisant of antimicrobial resistance, pandemics such as COVID-19, the threat of bioterrorist attacks, and the host-pathogen interactome model of disease.

\section{The Host-pathogen Interactome Model}

The use of immunomodulatory therapies to treat infectious disease, such as the recent success of dexamethasone to treat COVID-19, is indicative of the need to consider not only the disease-causing pathogen in therapeutic development, but the contributions of the host too. Casadevall and Pirofski's seminal damage-response framework is based on the fact that microbial pathogenesis, whether bacterial, fungal, parasitic or viral is the outcome of interactions between the host and a microorganism, and uses host damage as a common principle with which to define and measure this interaction (Fig. 1) ${ }^{12}$. Although it may not always be possible to account for both views in experimental design, conceptual consideration of the contributions of both the host and the microorganism to host damage is important to focus studies of microbial pathogenesis around a common principle, with the potential to unify the field of microbial pathogenesis and allied disciplines of immunology and vaccinology ${ }^{13-15}$.

Currently, classifications of microorganisms are based on phylogenetic groups (bacteria, fungi, parasites, viruses) ${ }^{16,17}$. Casadevall and Pirofski argue this system is limited by the fact that most members of any group are not pathogenic in a host; of 150,000 fungal species, for example, only around 150 are pathogenic for humans ${ }^{17}$. However, classifications based on the perceived capacity of a microorganism to cause disease are equally inadequate as changes in host immune function, ecology, and/or behaviour can render them obsolete ${ }^{18}$. As discussed later, classifying pathogens based on phylogenetic groups has been mirrored by the antimicrobial lexicon, which currently classifies antimicrobials according to their inhibitory activity against microbial phylogenetic groups (antibiotics, antifungals, antiparasitics, antivirals), encouraging a bias of therapeutic development towards pathogen-killing as opposed to hostpathogen interactome targeting and modulation ${ }^{19}$.

The use of host damage as the principle with which to categorise pathogens allows them to be classified according to the common denominator of pathogenic outcomes. Pathogens that cause similar types of diseases can be grouped together despite differences in phylogeny and growth characteristics. Pathogens grouped in a single class share similarities with regard to the shape of the damage-response curve as a function of the host immune response ${ }^{20,21}$. Ultimately, the host-pathogen interactome model crystallises the contemporary view of disease outcome as being determined both by the contributions of the host as well as the pathogen, a marked departure from the classical pathogen-centred view propounded in the early 20th century, with ramifications for microbial, immunological, and antimicrobial studies. 


\section{Host-modulating Antimicrobials}

The success of magic bullets and immunomodulatory therapies in the 20th century and the induction of the host-pathogen interactome model have propelled convergent research into antimicrobials with hostmodulating properties over the last few decades ${ }^{22}$. Such 'host-modulating antimicrobials' have become a desideratum for all disciplines of modern antimicrobial development due to lower probabilities of drug interactions (compared to the use of immunomodulatory therapies in conjunction with antimicrobials) associated with higher patient compliance, increased therapeutic range, and reduced contributions to antimicrobial resistance ${ }^{23}$.

Even before COVID-19, canonical antiviral drug development was being challenged. Traditional antivirals target virus proteins, incur higher development costs relative to antibiotics, offer limited therapeutic range, and are liable to escape mutant selection ${ }^{24}$. RNA viruses like SARS-CoV-2 are particularly limited in informational size, and have adapted to subvert multitasking host proteins ${ }^{25}$. Such solutions to the viral information economy paradox are conserved, offering the chance to leverage dependency on host proteins for host-directed antiviral therapies that are more effective, broad-acting, and economical ${ }^{26}$. Furthermore, host-directed therapies can synergise with increased availability of bioactive compounds (such as the development of nitazoxanide), and recent advances in precision medicine, such as genome editing, targeted delivery methods, and $\mathrm{RNAi}^{27}$. Indeed, such advances have been driven by an increasingly holistic appreciation of host-virus interactions, the cornerstone of the emerging field of neovirology ${ }^{28}$. A successful antiviral development paradigm will serve to complement rather than replace vaccine development for emerging viruses ${ }^{29}$. Indeed, host-directed antivirals can reduce replication and tissue tropism whilst maintaining viral antigenicity for vaccine development ${ }^{30,31}$.

As viruses are obligate parasites, key similarities exist between antiviral and antiparasitic development ${ }^{32}$. For example, antimicrobials that directly target Leishmania parasites has been limited by the capacity of Leishmania to rapidly evolve towards drug-resistance phenotypes, a property linked to its genome plasticity ${ }^{33}$. New strategies that are more refractory to the emergence of drug resistance target Leishmania viability indirectly via mechanisms of host-parasite interaction, including parasite-released ectokinases and host epigenetic regulation, which modulate host cell signalling and transcriptional regulation respectively ${ }^{34}$.

The past 15 years have seen an acceleration in antifungal drug development, culminating in an armamentarium of systemic antifungal agents including 5 classes of drugs including amphotericin $B$ $(\mathrm{AmB})$, the azoles, and the echinocandins ${ }^{35}$. Although their in vitro inhibitory and direct fungicidal effects are well characterised, antifungals also have indirect, immune system-mediated effects on fungi, which are only now coming to light ${ }^{36}$. Considering the substantial role of the host's immune response in regulating fungal infection, a better understanding of these immunopharmacological properties have been argued to be potentially instrumental in designing rational drug therapy for invasive fungal infection 
$(\mathrm{IFI})^{37}$. Utilisation of immunomodulatory properties of available antifungals has been suggested as a strategy to treat IFI 38 .

Overall, Casadevall and Pirofski envisioned that a consequence of the host-pathogen interactome model would be the unification of a lexicon which emphasised the difference between microbes and specific microbial attributes instead of highlighting common attributes. Without this unification, the disciplines of bacteriology, mycology, parasitology, and virology become increasingly insular, despite asking similar questions about the nature of infection. However, what is evident today is the movement of these disparate disciplines towards host-modulation, not unification. This is because the magic bullet model for antimicrobial development has cemented the fragmentary disposition of the disciplines of antibiotic, antifungal, antiparasitic, and antiviral development by classifying antimicrobials according to the associated inhibited pathogen. However, discoveries of conserved targetable moieties of the hostpathogen interactome across pathogen classes is representative of a movement towards unification of the microbial disciplines.

\section{Host Anti-infective Responses}

Several biotechnological advancements have made possible the characterisation of signalling pathways that are conserved across infection types ${ }^{39,40}$. Profiling global gene expression and sequence alignment to reference genomes enable isolation of differentially expressed genes pre- and post-infection 41,42 . Selected genes are assessed against repositories and online databases to probe enrichment of functional biological pathways, and subnetworks are constructed by comparing and connecting identified genes to curated protein-protein interaction databases ${ }^{43}$. Traditional monolayer cell cultures are also being supplanted by human in vitro 3D models which probe functional multicellular interactions of epithelial and immune cells (dendritic cells, neutrophils) ${ }^{44}$. Detailed mapping of host anti-infective responses in this way has led to the emergence of key signalling pathways that may be targeted by both existing and future pan-pathogen antimicrobials, such as STING and MAPK.

The first line of host defence against infectious agents involves activation of innate immune signalling pathways that recognise specific pathogen-associated molecular patterns (PAMPs) ${ }^{45,46}$. For example, RIG-I-like receptors (RLRs) have evolved to detect viral RNA species and to activate the production of host defence molecules and cytokines that stimulate adaptive immune responses; their regulation by hostderived ncRNAs is of particular interest ${ }^{47}$. In addition, host defence countermeasures, including the production of type I interferons (IFNs), can also be triggered by microbial DNA from bacteria, viruses and perhaps parasites and are regulated by the cytosolic sensor, stimulator of interferon genes (STING) ${ }^{48,49}$. The discovery of the STING signalling pathway has provided considerable insight into microbial pathogenesis, mechanisms of host defence, and causes of inflammatory disease and even cancer ${ }^{50}$. Regulation of the STING pathway has therefore been suggested as a pan-pathogen antimicrobial strategy ${ }^{51}$. Given the importance of STING as a mediator of both antiviral and pro-inflammatory responses to viral infection, it is interesting to consider last year it was shown to have a crucial role in 
replication of RV-A and RV-C rhinoviruse ${ }^{52}$. STING is relatively highly expressed in lung tissue and thus may contribute to protection against both bacterial and viral respiratory tract infection ${ }^{53}$. Considering azithromycin's ability to upregulate virus-induced type I interferon responses, its use as an antibiotic for pulmonary bacterial infections, and the fact that it has been described as a 'holy grail' to prevent exacerbations in chronic respiratory disease, a molecular mechanism of azithromycin and other macrolides via STING is possible $e^{54,55}$.

The MAP kinases (MAPKs), which include ERK, JNK, and p38 families, constitute an integral part of the host intracellular signalling network, essential for signal transduction from receptors and stimuli to biological reaction ${ }^{56-59}$. Appropriate functioning of MAPK signalling is thus critical to mount effective immune responses, and presents a broad-spectrum therapeutic target across pathogen classes, which drugs such as macrolides may exploit ${ }^{60,61}$. Macrolides are a class of diverse compounds which include antibiotics, antifungals, prokinetics, and immunosuppressants. The non-antimicrobial properties of macrolides have been suspected as far back as the 1960s and their successful treating of hyperinflammatory diseases such as diffuse panbronchiolitis (DPB) has served to extend their use to a number of chronic inflammatory diseases ${ }^{62}$. Macrolides have been shown to modulate intracellular MAPK, especially ERK1/2, and the NF-kB pathway downstream of ERK ${ }^{63}$. Due to the fact that these pathways exert plethoric cellular functions, including inflammatory cytokine production, cell proliferation, and mucin secretion, modulation of ERK1/2 and NF-kB can explain the majority of the reported immunomodulatory effects of macrolides ${ }^{64,65}$. Intriguingly, however, specific proteins and receptors targeted by macrolides that affect MAPK/NF-kB signalling have not yet been identified, offering an avenue for experimental verification. Indeed, putative binding molecule(s) may have multiple mechanisms of action. Overall, macrolide treatment of DPB, asthma, bronchiectasis, rhinosinusitis, and $\mathrm{CF}$ is made possible by polymodal modulation exerted at different levels of cellular signalling, yet among these, modulation of ERK1/2 and transcription factors is prominent, consistent, and clearly unrelated to antimicrobial properties ${ }^{66}$.

Due to its broad-spectrum anti-infective effect against bacteria, parasites, and viruses, several studies have sought to delineate the underlying molecular mechanism of nitazoxanide, a thiazolide drug ${ }^{67}$. Tizoxanide, the main active metabolite of nitazoxanide, exerts anti-inflammatory effects by inhibiting the production of pro-inflammatory cytokines and suppressing activation of the NF-kB and the MAPK signalling pathways in LPS-treated macrophage cells ${ }^{68}$. Similarly, niclosamide, a potential pan-pathogen antimicrobial, was found to inhibit MAPK/ERK in human glioblastoma studies, indicative of crosstalk between anti-infectives and anti-cancer therapeutics ${ }^{69}$. Moreover, ivermectin, a potential treatment for COVID-19, reverses drug resistance in cancer cells via the EGFR/ERK/Akt/NF-kB pathway ${ }^{70}$. During viral infection, signalling pathways that govern essential physiological roles, such as apoptosis, mitogenesis, cell proliferation, metabolism, and cytoskeletal reorganisation, can be usurped to the benefit of the virus. Considering the vital role played by the ERK/MAPK pathway in controlling diverse host physiological processes, it is not surprising that many viruses co-opt the pathway for their own biologic needs ${ }^{71}$. 
Development of new antiviral therapeutics based on clinical trials of ERK/MAPK inhibitors has been suggested for both DNA and RNA viruses, including SARS-CoV-2 recently ${ }^{72,73}$.

Autophagy signalling has also emerged as a host pharmacological target with broad-spectrum antiinfective potential. Recently, the Centers of Excellence for Translational Research (CETR) Program were founded to develop host-directed broad-spectrum anti-infective agents against pathogens with pandemic potential. According to their grant proposal, later funded by the National Institute of Allergy and Infectious Diseases (NIAID), 'broad-spectrum host-directed therapeutics, once approved for clinical use, can be deployed for emerging pathogens, new outbreaks, and pathogens engineered with ill-intent ${ }^{174}$. The goal of this proposal is to generate autophagy pathway-directed compounds that are active against a range of taxonomically-unrelated pathogens. To accomplish this, several strategies are being employed including targeting Beclin 1 complexes, genes and pathways for autophagy-dependent inhibition of bacterial infection, and Atg gene-dependent immunity ${ }^{75,76}$.

Virulence factors secreted by pathogens have co-evolved to manipulate host signalling pathways via a range of mechanisms, including constitutive pathway activation and subversion of critical signalling molecules. A major challenge is to determine enzymatic activities and host substrates for pathogen virulence factors that show no clear homology to eukaryotic proteins. Following from this, an even more complex challenge is to glean an understanding of the orchestra of factors within the host-pathogen interactome involved in successful infection. Both temporal and spatial considerations are essential for regulating host cells during infection, justifying the employment of model organisms to understand system-level effects of therapeutic intervention within a physiological context. Ultimately, the discovery of conserved anti-infective pathways is a landmark discovery, not only to incite unification of microbiological disciplines first envisioned by Casadevall and Pirofski, but also to mechanistically confirm the therapeutic success of existing antimicrobials which treat diseases pertaining to multiple pathogen classes.

\section{Anti-cancer Drugs As Broad-spectrum Anti-infectives}

Repositioning studies of anti-cancer drugs has led to the discovery that targeting certain host proteins yields broad-spectrum anti-infective activity, a further contribution away from the magic bullet paradigm ${ }^{77}$. Heat shock protein 90 (Hsp90) inhibitors and oestrogen receptor antagonists have unearthed therapeutic targets whose modulation may successfully treat malignancies as well as infection.

It has long been understood that microbes have exploited stress proteins as virulence factors for pathogenesis in their hosts ${ }^{78}$. Owing to its ability to sense and respond to the stress conditions, the molecular chaperone Hsp90 is one of the key stress proteins utilised by parasitic microbes ${ }^{79}$. There is growing evidence for the critical role played by Hsp90 in the growth of pathogenic organisms like Candida, Giardia, Plasmodium, Trypanosoma, among others ${ }^{80}$. The attractiveness of Hsp90 as an anticancer drug target has driven much research at laboratory, preclinical and clinical levels for several Hsp90 inhibitors as potential anti-cancer drugs ${ }^{81}$. Similarly, data pertaining to toxicity studies, pharmacokinetics 
and pharmacodynamics studies, dosage regime, drug related toxicities, dose limiting toxicities, and adverse drug reactions (ADRs) are available for Hsp90 inhibitors, making them attractive repositioning candidates $^{82}$.

The triphenylethylene class of selective oestrogen receptor modulators related to tamoxifen (TAM) has also shown activity against a range of pathogens including bacteria, fungi, parasites, and viruses ${ }^{83-85}$. It has been suggested that the broad spectrum of activity of TAM may be related to its amphipathic chemical properties: a hydrophobic aromatic core linked to a basic amine function ${ }^{86-89}$. Indeed, a TAM analogue lacking the amine function is rendered completely inactive as an antifungal ${ }^{90}$. In consideration of TAM's relatively low safety profile, medicinal chemistry-based optimisation of this pharmacologically attractive biologically-privileged scaffold may yield analogues with a balance of activity and toxicity useful within the anti-infective space.

While novel host-modulating properties of antimicrobials such as azithromycin and nitazoxanide are still being elucidated, host-directed anti-cancer drugs are emerging as antimicrobial treatments in their own right. The shared novelty of these therapeutics is the increased range of infection types able to be treated relative to pathogen-targeting antimicrobials, which are limited by the lack of conserved targetable moieties across pathogen types. Repositioning studies, both of anticancer drugs and antimicrobials, are the sole source of discovering clinically-viable pan-pathogen antimicrobials, and can therefore be used as a metric for formally characterising such drugs.

\section{Challenging The Antimicrobial Lexicon}

The term antibiotic - literally 'opposing life', derives from the Greek \vtı anti, "against" and ßíos bios, "life". This terminology has been extended to antifungal, antiparasitic, and antiviral drugs, reflecting a lexicon based on Ehrlich's magic bullet. Though this lexicon does not accurately reflect the array of interactions of modern antimicrobials with the host-pathogen interactome, it has not been problematic. Macrolide antibiotics, for example, have been used to treat bacterial infections with the knowledge that their host-modulating properties play a crucial role in pathogen clearance and disease management. The lexicon is challenged, however, when 1) antimicrobials of one class exhibit inhibitory or host-modulating properties characteristic of another class or 2) antimicrobials are used clinically to treat diseases pertaining to another pathogen class. The 'antibiotic' azithromycin and the 'antiparasitic agent' nitazoxanide are examples of antimicrobials that have done both ${ }^{91-94}$; azithromycin is clinically used against malarial parasites and nitazoxanide treats bacterial infections such as H. pylori ${ }^{95,96}$.

Both azithromycin and nitazoxanide are immunomodulatory agents. Nitazoxanide treatment results in an increase in IFNY- and IL-2-secreting CD4 + cells, TLR8-expressing monocytes, IFNa- and IFNß- mRNA expression, mRNA specific for type I IFN inducible genes, and mRNA specific for gene involved in MHC class I presentation ${ }^{97,98}$. The antiviral effects of nitzoxanide and its metabolite derivative tizoxanide result from the immunomodulatory activity stimulating a strong antiviral immune response mediated by both native and acquired mechanisms. In over 10 years of clinical use there has been no reported drug 
resistance by nitazoxanide treatment and attempts to produce drug resistance under laboratory conditions have generally not met with much success ${ }^{99}$. The immunomodulatory effects of azithromycin are more well-established, having been proven beneficial in treating a variety of chronic illnesses ${ }^{100,101}$. Azithromycin treatment results in decreased production of pro-inflammatory cytokines in the acute phase and promotes resolution of chronic inflammation in the later phases ${ }^{102}$. Specifically, azithromycin has direct activity on airway epithelial cells to maintain their function and reduce mucus secretion. These characteristics have resulted in the use of azithromycin in the management of a variety of chronic lung diseases including chronic obstructive pulmonary disease, cystic fibrosis (CF), non-CF bronchiectasis, bronchiolitis obliterans syndrome, diffuse panbronchiolitis, and asthma ${ }^{103}$. It is conceivable that the immunomodulatory properties of azithromycin and nitazoxanide facilitate their treatment of a range of infection types.

With such efficacy against a range of infectious diseases, to define azithromycin as an antibiotic or nitazoxanide as an antiparasitic agent oversimplifies their antimicrobial efficacy, precluding discovery of general infection mechanisms, rapid consideration for pandemics, and constructive unification of antimicrobial studies. Indeed, in the present pandemic, several studies addressed this by compiling panpathogen repositioning histories of therapeutic candidates ${ }^{104}$. In order to more accurately describe an antimicrobial candidate's properties as well as well to hasten their consideration for pandemics, we highlighted a system used to define antimicrobials based on both their ability to inhibit a pathogen in vitro and treat the corresponding disease in the clinical setting ${ }^{105}$. This system is based on Oprea and Overington's Drug Repositioning Evidence Level (DREL) classification scheme, which assigns a numerical value to the quality of evidence, which increases as evidence increases from in vitro investigations to animal models and human clinical trials (Table 1) ${ }^{106}$. From this scheme we determined four antimicrobial types (antibiotics, antifungals, antiparasitics, and antivirals) can correspond to four DREL numbers for a given antimicrobial. An antimicrobial that is used clinically as an antimalarial and an antiviral but has no evidence of efficacy against bacteria or fungi is a 0:0:4:4 antimicrobial. The order of the DREL numbers here are: antibiotic $=0$, antifungal $=0$, antiparasitic $=4$, antiviral $=4$. If no investigations have been conducted for an antimicrobial class for a given therapeutic, an ' $X$ ' may be used to denote this. 
Table 1

Oprea and Overington's DREL assessment of repositioning studies. A pan-pathogen antimicrobial is DREL 4 for two or more antimicrobial classes.

\begin{tabular}{|ll|}
\hline $\begin{array}{l}\text { Drug } \\
\text { repositioning } \\
\text { evidence level }\end{array}$ & Quality of scientific evidence \\
\hline 0 & No evidence; includes in silico predictions without confirmation \\
\hline 1 & In vitro studies with limited value for predicting in vivo/human situation \\
\hline 2 & Animal studies with hypothetical relevance in humans \\
\hline 4 & $\begin{array}{l}\text { Incomplete studies in humans at the appropriate dose e.g. proof of concept; few } \\
\text { cases from medical records; some clinical effects observed }\end{array}$ \\
\hline $\begin{array}{l}\text { Well-documented clinical end points observed for repositioned drug at doses } \\
\text { within safety limits }\end{array}$ \\
\hline
\end{tabular}

With an increasing number of repositioning studies being conducted worldwide, particularly in the midst of the current pandemic, a concomitant taxonomic structure can not only classify potential general antimicrobials, but direct future repositioning studies, facilitate comparative therapeutic investigations, and inform treatment application in global health emergencies ${ }^{107}$. From our classification system based on DREL we determined azithromycin is a 4:0:4:3 antimicrobial (Table 2). Pan-pathogen antimicrobials can therefore simply be defined as antimicrobials that are DREL $=4$ for two antimicrobial classes. Previously the term 'broad-spectrum therapeutic' has been propounded to denote this; 'pan-pathogen antimicrobial' and 'broad-spectrum anti-infective' are preferred alternatives ${ }^{108}$.

Table 2

BFPV classification of potential pan-pathogen antimicrobials. Each number represents a DREL score for a particular antimicrobial class for a given therapeutic. ' $X$ ' denotes no investigations conducted.

\begin{tabular}{|c|c|c|c|c|}
\hline & Antibiotic & Antifungal & Antiparasitic & Antiviral \\
\hline Azithromycin & 4 & $x$ & $4^{118}$ & $3^{119-121}$ \\
\hline Ivermectin & $1^{122}$ & $x$ & 4 & $3^{123,124}$ \\
\hline Niclosamide & $2^{125-127}$ & $x$ & 4 & $2^{128}$ \\
\hline Nitazoxanide & $3^{129,130}$ & $\mathrm{x}$ & 4 & $3^{131}$ \\
\hline
\end{tabular}

The system, hereby termed the BFPV classification scheme (for antiBiotic, antiFungal, antiParasitic, antiViral; alternatively: Bacterial infection, Fungal infection, Parasitic infection, Viral infection) scores the effectiveness of an antimicrobial for a particular pathogen type using three major parameters: in vitro activity, in vivo activity, and clinical effectiveness. This represents a departure from a magic bulletoriented lexicon by defining an antimicrobial not solely by its ability to inhibit a pathogen but by its ability 
to shift the damage-response curve towards mitigating damage within the more holistic, physiological context. As pan-pathogen antimicrobial development matures as a discipline in its own right, the DREL system can be replaced by a more accurate framework that classifies drugs according to the degree to which they reduce damage resulting from the host-pathogen interaction as a function of the host immune response, perhaps based on Casadevall and Pirofski's 'Class' scheme for host-pathogen interactomes ${ }^{20}$. As with the damage-response framework, associated classifications and predictions are subject to further experimental studies to validate or refute the framework's ability to account for the perturbation of therapeutic intervention on the damage-response curve during microbial pathogenesis.

\section{Bioterrorism And Pandemics}

Upon characterising pan-pathogen antimicrobials, the pertinent question arises: so what? The key advantage of pan-pathogen antimicrobials over single-target antimicrobials is the ability to account for diseases that have not yet emerged either by natural means or by human engineering. In other words, such drugs are preparatory to pandemics and bioterrorism, and so their health and economic value is significant both for governments and enterprise.

Bioterrorism is a unique topic in the literature, appearing at the confluence of research publications and government mitigation strategy reports. The term 'bioterrorism' differs from 'biowarfare' in the sense that the threat originates from terrorist groups rather than nation states. Unlike conventional warfare, where the enemy and likely mode of warfare are known and understood, terrorism is less easy to predict. At a Winter Meeting of the British Thoracic Society in 2004, the British Association for Lung Research organised a symposium entitled 'Bioterrorism: The Lung Under Attack' in which the lung was identified as a physiological target for all compounds that can be dispersed as gases or aerosols ${ }^{109}$. Understanding the effects of these substances on the lung was identified as a key consideration in the mitigation of bioterrorist threats ${ }^{110}$. While bioterrorism is often taken to mean acts that involve the use of biological materials such as bacteria, bacterial spores, and viruses, this is a limited definition. Indeed, terrorists can deploy a range of agents including classical chemical warfare agents from WWII. However, for the scope of this review and in consideration of the recent COVID-19 pandemic, the definition is herein limited to biologically viable particles i.e. bacteria, fungi, parasites, and viruses.

COVID-19 emerged as a respiratory viral pandemic, leading to the use of steroid treatments to curb hyperinflammatory symptoms in affected patients. Prior to the pandemic, however, the use of panpathogen antimicrobial agents to treat inflammatory of the lung was increasing. For example, in vivo studies showed that ivermectin is an effective suppressor of inflammation, rationalising its use as a treatment of non-infectious airway inflammatory diseases such as allergic asthma ${ }^{111}$. Inhibition of mucus and cytokine release, bronchorelaxation, and reported antibacterial effects have also made niclosamide, another potential pan-pathogen antimicrobial, a potentially suitable drug for the treatment of inflammatory airway diseases such as cystic fibrosis, asthma, and COPD ${ }^{112}$. Antagonists of the $\mathrm{Ca}^{2+}$ activated $\mathrm{Cl}^{-}$channel, TMEM16A, offers a new mechanism to bronchodilate airways and block the 
multiple contractiles operating in severe disease ${ }^{113}$. Screening a library of 580,000 compounds identified niclosamide and nitazoxanide as potent TMEM16A antagonists blocking airway smooth muscle depolarisation and contraction ${ }^{114}$. While isoproterenol, a canonical $\beta$-agonist, only showed partial bronchodilation of airways, niclosamide and nitazoxanide showed full effects, representing an important treatment for patients with severe asthma and COPD. That current pan-pathogen antimicrobials are repositioned for a multitude of respiratory diseases is a further reason to consider them for future outbreaks and emphasises the need for further research to unearth underlying mechanisms in relation to physiological context.

The idea for 'general' drugs for pandemics is not new. In 2007, the Strategic Plan for Biodefense Research by the U.S. Department of Health and Human Services (HHS) and the National Institute of Allergy and Infectious Diseases (NIAID) stated that 'anti-infectives with broad-spectrum activity directed at common, invariable, and essential components of different classes of microbes could potentially be effective against both traditional and non-traditional threats' ${ }^{115}$. However, developing broad-spectrum drugs has proven difficult because pharmaceutical companies and regulators are more accustomed to developing and evaluating drugs that target a specific disease: the 'one bug-one drug' paradigm. Similarly, the Transformational Medical Technologies (TMT) initiative, established in the U.S. Department of Defense in 2006, was conceived as a five-year, US\$1.5-billion project that would accelerate the development of countermeasures such as 'broad-spectrum' therapies that would work against multiple bacterial and viral pathogens, especially haemorrhagic fever viruses such as Ebola and Marburg ${ }^{116}$. Indeed, the Oxford dictionary definition for the term 'general' is: 'affecting or concerning all things; broad, comprehensive, and widespread'. There are no pan-pathogen inhibitors that target conserved properties across pathogen classes. However, by targeting the host-pathogen interactome, host-modulating antimicrobials overcome this limitation, being able to treat diseases across pathogen classes. This property is what makes hostmodulating antimicrobials the first antimicrobial class to display 'pan-pathogen' properties. Pan-pathogen antimicrobials, due to their clinical safety profile for a myriad of diseases and anti-infective efficacy against a range of pathogens, may therefore satisfy the requirements for a new 'general' class of antimicrobials for pandemics, even as stipulated by the current director of NIAID and chief medical advisor to the current U.S. President (Fig. 2) ${ }^{117}$.

\section{Discussion}

For over a century, drug development has been tailored towards known diseases and pathogens. In order to prepare for a novel pathogen, a generalised drug development strategy is required, cognisant of a range infection types. In theory, both magic bullet and magic blanket paradigms can yield pan-pathogen antimicrobials. In reality, only one has. Host-directed therapies that interfere with host cell mechanisms, enhance immune responses, and reduce exacerbated inflammation or balance host reactions at the site of pathology hold promise for the selective and symptomatic treatment of infectious diseases. In viral infections such as COVID-19, targeting host cell factors and pathways that are required by a given virus for productive replication and spread offers the opportunity for broad-acting treatments. Knowledge of 
host cell factors and pathways commonly used by different pathogens can be greatly enhanced by probing host targets of the pan-pathogen antimicrobials identified in this review. Consequently, as antibiotics and antivirals of the 20th century became more specific for the bacterium and virus, panpathogen antimicrobials of the 21 st century will be increasingly specific for the host (Table 3 ).

Table 3

Comparison of two antimicrobial paradigms. Classical antimicrobials contending with a single target exploit phenotypic differences between the host and pathogen. Host-modulating antimicrobials target pathogen properties as developed through co-evolution with the host. Consequently, while broad-spectrum antivirals like remdesivir are magic bullets exclusively targeting viruses, azithromycin and nitazoxanide's immunomodulatory properties have rationalised their use against bacterial, parasitic, and even viral infections. Pan-pathogen antimicrobials, therefore, have emerged from magic blanket, not magic bullet, development.

\begin{tabular}{|lll|}
\hline & Magic bullet & Magic blanket \\
\hline Drug class & Antimicrobial & Host-modulating antimicrobial \\
\hline Target & Pathogen & Host-pathogen interactome \\
\hline Drugs & Antibiotics, antifungals, antiparasitics, antivirals & BFPV antimicrobials \\
\hline
\end{tabular}

Development of antimicrobials which target the host-pathogen interactome has more opportunity for growth relative to pathogen-targeting antimicrobials due to the number of factors yet to be discovered. Great therapeutic potential also derives from the fact that pharmacological modulation of infectious diseases is considered within an acute, not chronic, pathological context, allowing for clinical application of more powerful modulators. A caveat, however, is the dynamic nature of the host-pathogen interactome across disease pathogenesis. Indeed, a crucial difference between targeting the host-pathogen interactome and targeting the pathogen is temporality, and great emphasis has been placed on the need to develop biomarkers that accurately reflect the host immunological signature in order to effectively inform application of host modulators. Biomarkers indicate the stage of infection, allow the monitoring of treatment success or failure, provide information on organ involvement and type of inflammation, and permit patient stratification for selected immunomodulatory therapies. As biomarkers become increasingly accurate at reflecting immune status, so the effects of host-modulating antimicrobials can be better predicted. That being said, most immunomodulatory strategies have been developed without understanding the full complexity of their interaction with the host and hence the fact that we do not yet fully understand the complexity of the host-drug interaction of host-modulating antimicrobials need not preclude development and application of host-modulating therapies; rather identification of successful magic blankets can inspire further investigations into the nature and context of their pharmacological targets. As was the case for magic bullets a century ago, current understanding of host-modulating antimicrobials is still in its infancy, and is an attractive field for further research.

\section{Conclusion And Future Directions}


This review represents the first time pan-pathogen antimicrobials have been formally identified and characterised, and the first time such drugs have been associated with 'magic blanket' antimicrobial development. Azithromycin, ivermectin, niclosamide, and nitazoxanide assert a unique advantage over traditional antibiotics and antivirals in their ability to treat a wider range of infectious diseases by regulating the host-pathogen interactome. Like with immunomodulatory drugs, however, the use of biomarkers will inform the appropriate application and dosage stipulations of these drugs across infection types. Tempered by their contribution to antimicrobial resistance, such broad-acting drugs may constitute an 'emergency treatment class' for global health emergencies such as COVID-19, future respiratory pandemics, and potential bioterrorist attacks; a property reinforced by their extensive repositioning for pulmonary disorders and substantial affordability and international availability relative to antibody, vaccine, and plasma-based strategies. Ultimately, formal recognition of pan-pathogen antimicrobials can facilitate discovery of conserved infective and anti-infective mechanisms and pharmacophores, enabling the long-campaigned unification of the disparate fields of bacteriology, fungology, parasitology, and virology, while heralding a paradigm of antimicrobial development conceptually distinct from the antibiotic era of the 20th century.

\section{Declarations}

\section{Acknowledgements}

Many thanks to our colleagues at the Department of Biochemistry and Trinity College, University of Oxford.

\section{Availability of data and material}

Not applicable.

\section{Authors' contributions}

PP conceived, wrote, and edited the manuscript.

\section{Code availability}

Not applicable.

\section{Conflict of interest}

The author declares no conflict of interest.

\section{Consent to participate}

Not applicable.

\section{Consent for publication}


Not applicable.

\section{Ethics approval}

Not applicable.

\section{Funding statement}

This research received no funding.

\section{References}

1. Baxter AG. Louis Pasteur's beer of revenge. Nat Rev Immunol. 2001 Dec;1(3):229 - 32. doi: 10.1038/35105083. PMID: 11905832.

2. Strebhardt K, Ullrich A. Paul Ehrlich's magic bullet concept: 100 years of progress. Nat Rev Cancer. 2008 Jun;8(6):473-80. doi: 10.1038/nrc2394. Epub 2008 May 12. PMID: 18469827.

3. Neu HC, Gootz TD. Antimicrobial Chemotherapy. In: Baron S, editor. Medical Microbiology. 4th ed. Galveston (TX): University of Texas Medical Branch at Galveston; 1996. Chapter 11. PMID: 21413283.

4. McNaught W. Limitations of the germ theory. Lancet. 1968 Jul 27;2(7561):220. doi: 10.1016/s01406736(68)92655-x. PMID: 4173435.

5. Pirofski LA, Casadevall A. Immunomodulators as an antimicrobial tool. Curr Opin Microbiol. 2006 Oct;9(5):489-95. doi: 10.1016/j.mib.2006.08.004. Epub 2006 Aug 22. PMID: 16931122; PMCID: PMC7108246.

6. Ramamurthy D, Nundalall T, Cingo S, Mungra N, Karaan M, Naran K, Barth S. Recent Advances in Immunotherapies Against Infectious Diseases. Immunotherapy Advances. 2020 Nov 25:Itaa007. doi: 10.1093/immadv/ltaa007. PMCID: PMC7717302.

7. Pathogenesis: of host and pathogen. Nat Immunol. 2006 Mar;7(3):217. doi: 10.1038/ni0306-217. PMID: 16482163.

8. Rouse BT, Sehrawat S. Immunity and immunopathology to viruses: what decides the outcome? Nat Rev Immunol. 2010 Jul;10(7):514-26. doi: 10.1038/nri2802. PMID: 20577268; PMCID: PMC3899649.

9. Chitalia VC, Munawar AH. A painful lesson from the COVID-19 pandemic: the need for broadspectrum, host-directed antivirals. J Transl Med. 2020 Oct 15;18(1):390. doi: 10.1186/s12967-02002476-9. PMID: 33059719; PMCID: PMC7558548.

10. Kelleni MT. Tocilizumab, Remdesivir, Favipiravir, and Dexamethasone Repurposed for COVID-19: a Comprehensive Clinical and Pharmacovigilant Reassessment. SN Compr Clin Med. 2021 Feb 19:15. doi: 10.1007/s42399-021-00824-4. Epub ahead of print. PMID: 33644693; PMCID: PMC7894610.

11. Crua Asensio N, Muñoz Giner E, de Groot NS, Torrent Burgas M. Centrality in the host-pathogen interactome is associated with pathogen fitness during infection. Nat Commun. 2017 Jan 
16;8:14092. doi: 10.1038/ncomms14092. PMID: 28090086; PMCID: PMC5241799.

12. Casadevall A, Pirofski LA. Host-pathogen interactions: basic concepts of microbial commensalism, colonization, infection, and disease. Infect Immun. 2000 Dec;68(12):6511-8. doi:

10.1128/IAI.68.12.6511-6518.2000. PMID: 11083759; PMCID: PMC97744.

13. Casadevall A, Pirofski LA. Host-pathogen interactions: redefining the basic concepts of virulence and pathogenicity. Infect Immun. 1999 Aug;67(8):3703-13. doi: 10.1128/IAI.67.8.3703-3713.1999. PMID: 10417127; PMCID: PMC96643.

14. Nash AA, Dalziel RG, Fitzgerald JR. Mechanisms of Cell and Tissue Damage. Mims' Pathogenesis of Infectious Disease. 2015:171-231. doi: 10.1016/B978-0-12-397188-3.00008-1. Epub 2015 Feb 6. PMCID: PMC7158287.

15. Sen R, Nayak L, De RK. A review on host-pathogen interactions: classification and prediction. Eur J Clin Microbiol Infect Dis. 2016 Oct;35(10):1581-99. doi: 10.1007/s10096-016-2716-7. Epub 2016 Jul 29. PMID: 27470504.

16. Pitt TL, Barer MR. Classification, identification and typing of micro-organisms. Medical Microbiology. 2012:24-38. doi: 10.1016/B978-0-7020-4089-4.00018-4. Epub 2012 May 24. PMCID: PMC7171901.

17. Köhler JR, Casadevall A, Perfect J. The spectrum of fungi that infects humans. Cold Spring Harb Perspect Med. 2014 Nov 3;5(1):a019273. doi: 10.1101/cshperspect.a019273. PMID: 25367975; PMCID: PMC4292074.

18. Pérez JC, Kumamoto CA, Johnson AD. Candida albicans commensalism and pathogenicity are intertwined traits directed by a tightly knit transcriptional regulatory circuit. PLoS Biol. 2013;11(3):e1001510. doi: 10.1371/journal.pbio.1001510. Epub 2013 Mar 19. PMID: 23526879; PMCID: PMC3601966.

19. Colson P, Raoult D. Fighting viruses with antibiotics: an overlooked path. Int J Antimicrob Agents. 2016 Oct;48(4):349-52. doi: 10.1016/j.ijantimicag.2016.07.004. Epub 2016 Aug 5. PMID: 27546219; PMCID: PMC7134768.

20. Casadevall A, Pirofski LA. The damage-response framework of microbial pathogenesis. Nat Rev Microbiol. 2003 Oct;1(1):17-24. doi: 10.1038/nrmicro732. PMID: 15040176; PMCID: PMC7097162.

21. Pirofski LA, Casadevall A. Pathogenesis of COVID-19 from the Perspective of the Damage-Response Framework. mBio. 2020 Jul 2;11(4):e01175-20. doi: 10.1128/mBio.01175-20. PMID: 32616514; PMCID: PMC7338079.

22. Tauber SC, Nau R. Immunomodulatory properties of antibiotics. Curr Mol Pharmacol. 2008 Jan;1(1):68-79. PMID: 20021425.

23. Pasquale TR, Tan JS. Nonantimicrobial effects of antibacterial agents. Clin Infect Dis. 2005 Jan 1;40(1):127 - 35. doi: 10.1086/426545. Epub 2004 Dec 1. PMID: 15614702.

24. Heaton SM. Harnessing host-virus evolution in antiviral therapy and immunotherapy. Clin Transl Immunology. 2019 Jul 8;8(7):e1067. doi: 10.1002/cti2.1067. PMID: 31312450; PMCID: PMC6613463. 
25. Duffy S. Why are RNA virus mutation rates so damn high? PLoS Biol. 2018 Aug 13;16(8):e3000003. doi: 10.1371/journal.pbio.3000003. PMID: 30102691; PMCID: PMC6107253.

26. Prussia A, Thepchatri P, Snyder JP, Plemper RK. Systematic approaches towards the development of host-directed antiviral therapeutics. Int J Mol Sci. 2011;12(6):4027-52. doi: 10.3390/ijms12064027. Epub 2011 Jun 15. PMID: 21747723; PMCID: PMC3131607.

27. Estrin MA, Hussein ITM, Puryear WB, Kuan AC, Artim SC, Runstadler JA. Host-directed combinatorial RNAi improves inhibition of diverse strains of influenza A virus in human respiratory epithelial cells. PLoS One. 2018 May 18;13(5):e0197246. doi: 10.1371/journal.pone.0197246. PMID: 29775471; PMCID: PMC5959063.

28. Watanabe T, Kawaoka Y. [Neo-Virology: the raison d'etre of viruses]. Uirusu. 2016;66(2):155-162. Japanese. doi: 10.2222/jsv.66.155. PMID: 29081467.

29. Wang QC, Nie QH, Feng ZH. RNA interference: antiviral weapon and beyond. World J Gastroenterol. 2003 Aug;9(8):1657-61. doi: 10.3748/wjg.v9.i8.1657. PMID: 12918096; PMCID: PMC4611519.

30. Guo X, Carroll JW, Macdonald MR, Goff SP, Gao G. The zinc finger antiviral protein directly binds to specific viral mRNAs through the CCCH zinc finger motifs. J Virol. 2004 Dec;78(23):12781-7. doi: 10.1128/JVI.78.23.12781-12787.2004. PMID: 15542630; PMCID: PMC525010.

31. Mihara T, Nishimura Y, Shimizu Y, Nishiyama H, Yoshikawa G, Uehara H, Hingamp P, Goto S, Ogata H. Linking Virus Genomes with Host Taxonomy. Viruses. 2016 Mar 1;8(3):66. doi: 10.3390/v8030066. PMID: 26938550; PMCID: PMC4810256.

32. Godkin A, Smith KA. Chronic infections with viruses or parasites: breaking bad to make good. Immunology. 2017 Apr;150(4):389-396. doi: 10.1111/imm.12703. Epub 2017 Jan 19. PMID: 28009488; PMCID: PMC5343343.

33. Ponte-Sucre A, Gamarro F, Dujardin JC, Barrett MP, López-Vélez R, García-Hernández R, Pountain AW, Mwenechanya R, Papadopoulou B. Drug resistance and treatment failure in leishmaniasis: A 21st century challenge. PLoS NegI Trop Dis. 2017 Dec 14;11(12):e0006052. doi: 10.1371/journal.pntd.0006052. PMID: 29240765; PMCID: PMC5730103.

34. Lamotte S, Späth GF, Rachidi N, Prina E. The enemy within: Targeting host-parasite interaction for antileishmanial drug discovery. PLoS Negl Trop Dis. 2017 Jun 8;11(6):e0005480. doi: 10.1371/journal.pntd.0005480. PMID: 28594938; PMCID: PMC5464532.

35. You L, Yao C, Yang F, Yang Q, Lan J, Song X, Shen J, Sheng X, Chen X, Tang H, Jiang H, Wu H, Qian S, Meng H. Echinocandins versus Amphotericin B Against Candida tropicalis Fungemia in Adult Hematological Patients with Neutropenia: A Multicenter Retrospective Cohort Study. Infect Drug Resist. 2020 Jul 10;13:2229-2235. doi: 10.2147/IDR.S258744. PMID: 32764998; PMCID: PMC7360406.

36. Sam QH, Yew WS, Seneviratne CJ, Chang MW, Chai LYA. Immunomodulation as Therapy for Fungal Infection: Are We Closer? Front Microbiol. 2018 Jul 25;9:1612. doi: 10.3389/fmicb.2018.01612. PMID: 30090091; PMCID: PMC6068232. 
37. Ademe M. Immunomodulation for the Treatment of Fungal Infections: Opportunities and Challenges. Front Cell Infect Microbiol. 2020 Sep 15;10:469. doi: 10.3389/fcimb.2020.00469. PMID: 33042859; PMCID: PMC7522196.

38. Simitsopoulou M, Roilides E, Walsh TJ. Immunomodulatory properties of antifungal agents on phagocytic cells. Immunol Invest. 2011;40(7-8):809 - 24. doi: 10.3109/08820139.2011.615877. PMID: 21985307.

39. Alto NM, Orth K. Subversion of cell signaling by pathogens. Cold Spring Harb Perspect Biol. 2012 Sep 1;4(9):a006114. doi: 10.1101/cshperspect.a006114. PMID: 22952390; PMCID: PMC3428769.

40. Pieters VM, Co IL, Wu NC, McGuigan AP. Applications of Omics Technologies for Three-Dimensional In Vitro Disease Models. Tissue Eng Part C Methods. 2021 Mar;27(3):183-199. doi:

10.1089/ten.TEC.2020.0300. Epub 2021 Feb 22. PMID: 33406987.

41. Ling KM, Garratt LW, Gill EE, Lee AHY, Agudelo-Romero P, Sutanto EN, losifidis T, Rosenow T, Turvey SE, Lassmann T, Hancock REW, Kicic A, Stick SM. Rhinovirus Infection Drives Complex Host Airway Molecular Responses in Children With Cystic Fibrosis. Front Immunol. 2020 Jul 16;11:1327. doi: 10.3389/fimmu.2020.01327. PMID: 32765492; PMCID: PMC7378398.

42. Wang Z, Gerstein M, Snyder M. RNA-Seq: a revolutionary tool for transcriptomics. Nat Rev Genet. 2009 Jan;10(1):57-63. doi: 10.1038/nrg2484. PMID: 19015660; PMCID: PMC2949280.

43. Pattin KA, Moore JH. Role for protein-protein interaction databases in human genetics. Expert Rev Proteomics. 2009 Dec;6(6):647-59. doi: 10.1586/epr.09.86. PMID: 19929610; PMCID: PMC2813729.

44. Jensen C, Teng Y. Is It Time to Start Transitioning From 2D to 3D Cell Culture? Front Mol Biosci. 2020 Mar 6;7:33. doi: 10.3389/fmolb.2020.00033. PMID: 32211418; PMCID: PMC7067892.

45. Mogensen TH. Pathogen recognition and inflammatory signaling in innate immune defenses. Clin Microbiol Rev. 2009 Apr;22(2):240 - 73, Table of Contents. doi: 10.1128/CMR.00046-08. PMID: 19366914; PMCID: PMC2668232.

46. Gürtler C, Bowie AG. Innate immune detection of microbial nucleic acids. Trends Microbiol. 2013 Aug;21(8):413-20. doi: 10.1016/j.tim.2013.04.004. Epub 2013 May 29. PMID: 23726320; PMCID: PMC3735846.

47. Rehwinkel J, Gack MU. RIG-I-like receptors: their regulation and roles in RNA sensing. Nat Rev Immunol. 2020 Sep;20(9):537-551. doi: 10.1038/s41577-020-0288-3. Epub 2020 Mar 13. PMID: 32203325; PMCID: PMC7094958.

48. Li Z, Cai S, Sun Y, Li L, Ding S, Wang X. When STING Meets Viruses: Sensing, Trafficking and Response. Front Immunol. 2020 Sep 29;11:2064. doi: 10.3389/fimmu.2020.02064. PMID: 33133062; PMCID: PMC7550420.

49. Marinho FV, Benmerzoug S, Oliveira SC, Ryffel B, Quesniaux VFJ. The Emerging Roles of STING in Bacterial Infections. Trends Microbiol. 2017 Nov;25(11):906-918. doi: 10.1016/j.tim.2017.05.008. Epub 2017 Jun 15. PMID: 28625530; PMCID: PMC5650497.

50. Su T, Zhang Y, Valerie K, Wang XY, Lin S, Zhu G. STING activation in cancer immunotherapy. Theranostics. 2019 Oct 15;9(25):7759-7771. doi: 10.7150/thno.37574. PMID: 31695799; PMCID: 
PMC6831454.

51. Ahn J, Barber GN. STING signaling and host defense against microbial infection. Exp Mol Med. 2019 Dec 11;51(12):1-10. doi: 10.1038/s12276-019-0333-0. PMID: 31827069; PMCID: PMC6906460.

52. McKnight KL, Swanson KV, Austgen K, Richards C, Mitchell JK, McGivern DR, Fritch E, Johnson J, Remlinger K, Magid-Slav M, Kapustina M, You S, Lemon SM. Stimulator of interferon genes (STING) is an essential proviral host factor for human rhinovirus species A and C. Proc Natl Acad Sci U S A. 2020 Nov 3;117(44):27598-27607. doi: 10.1073/pnas.2014940117. Epub 2020 Oct 15. PMID: 33060297; PMCID: PMC7959528.

53. Savigny F, Schricke C, Lacerda-Queiroz N, Meda M, Nascimento M, Huot-Marchand S, Da Gama Monteiro F, Ryffel B, Gombault A, Le Bert M, Couillin I, Riteau N. Protective Role of the Nucleic Acid Sensor STING in Pulmonary Fibrosis. Front Immunol. 2021 Jan 8;11:588799. doi:

10.3389/fimmu.2020.588799. PMID: 33488589; PMCID: PMC7820752.

54. Welte T. Azithromycin: The Holy Grail to Prevent Exacerbations in Chronic Respiratory Disease? Am J Respir Crit Care Med. 2019 Aug 1;200(3):269-270. doi: 10.1164/rccm.201903-0706ED. PMID: 30986361; PMCID: PMC6680302.

55. DiNicolantonio JJ, Barroso-Aranda J, McCarty MF. Azithromycin and glucosamine may amplify the type 1 interferon response to RNA viruses in a complementary fashion. Immunol Lett. 2020 Dec;228:83-85. doi: 10.1016/j.imlet.2020.09.008. Epub 2020 Sep 28. PMID: 33002511; PMCID: PMC7521214.

56. Braicu C, Buse M, Busuioc C, Drula R, Gulei D, Raduly L, Rusu A, Irimie A, Atanasov AG, Slaby O, Ionescu C, Berindan-Neagoe I. A Comprehensive Review on MAPK: A Promising Therapeutic Target in Cancer. Cancers (Basel). 2019 Oct 22;11(10):1618. doi: 10.3390/cancers11101618. PMID: 31652660; PMCID: PMC6827047.

57. Kuriakose S, Onyilagha C, Singh R, Olayinka-Adefemi F, Jia P, Uzonna JE. TLR-2 and MyD88Dependent Activation of MAPK and STAT Proteins Regulates Proinflammatory Cytokine Response and Immunity to Experimental Trypanosoma congolense Infection. Front Immunol. 2019 Nov 22;10:2673. doi: 10.3389/fimmu.2019.02673. PMID: 31824484; PMCID: PMC6883972.

58. Sharp LL, Schwarz DA, Bott CM, Marshall CJ, Hedrick SM. The influence of the MAPK pathway on T cell lineage commitment. Immunity. 1997 Nov;7(5):609 - 18. doi: 10.1016/s1074-7613(00)80382-9. PMID: 9390685.

59. Rincón M, Flavell RA, Davis RJ. Signal transduction by MAP kinases in T lymphocytes. Oncogene. 2001 Apr 30;20(19):2490-7. doi: 10.1038/sj.onc.1204382. PMID: 11402343.

60. Krachler AM, Woolery AR, Orth K. Manipulation of kinase signaling by bacterial pathogens. J Cell Biol. 2011 Dec 26;195(7):1083-92. doi: 10.1083/jcb.201107132. Epub 2011 Nov 28. PMID: $22123833 ;$ PMCID: PMC3246894.

61. Kumar R, Khandelwal N, Thachamvally R, Tripathi BN, Barua S, Kashyap SK, Maherchandani S, Kumar N. Role of MAPK/MNK1 signaling in virus replication. Virus Res. 2018 Jul 15;253:48-61. doi: 10.1016/j.virusres.2018.05.028. Epub 2018 Jun 1. PMID: 29864503; PMCID: PMC7114592. 
62. Zhanel GG, Dueck M, Hoban DJ, Vercaigne LM, Embil JM, Gin AS, Karlowsky JA. Review of macrolides and ketolides: focus on respiratory tract infections. Drugs. 2001;61(4):443 - 98. doi: 10.2165/00003495-200161040-00003. PMID: 11324679.

63. Kanoh S, Rubin BK. Mechanisms of action and clinical application of macrolides as immunomodulatory medications. Clin Microbiol Rev. 2010 Jul;23(3):590-615. doi: 10.1128/CMR.00078-09. PMID: 20610825; PMCID: PMC2901655.

64. Bosnar M, Čužić S, Bošnjak B, Nujić K, Ergović G, Marjanović N, Pašalić I, Hrvačić B, Polančec D, Glojnarić I, Eraković Haber V. Azithromycin inhibits macrophage interleukin-1 $\beta$ production through inhibition of activator protein-1 in lipopolysaccharide-induced murine pulmonary neutrophilia. Int Immunopharmacol. 2011 Apr;11(4):424-34. doi: 10.1016/j.intimp.2010.12.010. Epub 2010 Dec 30. PMID: 21195124.

65. Yang J. Mechanism of azithromycin in airway diseases. J Int Med Res. 2020 Jun;48(6):300060520932104. doi: 10.1177/0300060520932104. PMID: 32589092; PMCID: PMC7323306.

66. Mohanta TK, Arina P, Sharma N, Defilippi P. Role of azithromycin in antiviral treatment: enhancement of interferon-dependent antiviral pathways and mitigation of inflammation may rely on inhibition of the MAPK cascade? Am J Transl Res. 2020 Dec 15;12(12):7702-7708. PMID: 33437355; PMCID: PMC7791480.

67. Singh N, Narayan S. Nitazoxanide: A Broad Spectrum Antimicrobial. Med J Armed Forces India. 2011 Jan;67(1):67 - 8. doi: 10.1016/S0377-1237(11)80020-1. Epub 2011 Jul 21. PMID: 27365765; PMCID: PMC4920633.

68. Shou J, Kong X, Wang X, Tang Y, Wang C, Wang M, Zhang L, Liu Y, Fei C, Xue F, Li J, Zhang K. Tizoxanide Inhibits Inflammation in LPS-Activated RAW264.7 Macrophages via the Suppression of NF-KB and MAPK Activation. Inflammation. 2019 Aug;42(4):1336-1349. doi: 10.1007/s10753-01900994-3. PMID: 30937840.

69. Cheng B, Morales LD, Zhang Y, Mito S, Tsin A. Niclosamide induces protein ubiquitination and inhibits multiple pro-survival signaling pathways in the human glioblastoma U-87 MG cell line. PLoS One. 2017 Sep 6;12(9):e0184324. doi: 10.1371/journal.pone.0184324. PMID: 28877265; PMCID: PMC5587337.

70. Jiang $L$, Wang $P$, Sun $Y J$, Wu YJ. Ivermectin reverses the drug resistance in cancer cells through EGFR/ERK/Akt/NF-kB pathway. J Exp Clin Cancer Res. 2019 Jun 18;38(1):265. doi: 10.1186/s13046019-1251-7. PMID: 31215501; PMCID: PMC6580523.

71. Kindrachuk J, Ork B, Hart BJ, Mazur S, Holbrook MR, Frieman MB, Traynor D, Johnson RF, Dyall J, Kuhn JH, Olinger GG, Hensley LE, Jahrling PB. Antiviral potential of ERK/MAPK and PI3K/AKT/mTOR signaling modulation for Middle East respiratory syndrome coronavirus infection as identified by temporal kinome analysis. Antimicrob Agents Chemother. 2015 Feb;59(2):1088-99. doi: 10.1128/AAC.03659-14. Epub 2014 Dec 8. PMID: 25487801; PMCID: PMC4335870. 
72. DuShane JK, Maginnis MS. Human DNA Virus Exploitation of the MAPK-ERK Cascade. Int J Mol Sci. 2019 Jul 12;20(14):3427. doi: 10.3390/ijms20143427. PMID: 31336840; PMCID: PMC6679023.

73. Ghasemnejad-Berenji M, Pashapour S. SARS-CoV-2 and the Possible Role of Raf/MEK/ERK Pathway in Viral Survival: Is This a Potential Therapeutic Strategy for COVID-19? Pharmacology. 2021;106(12):119-122. doi: 10.1159/000511280. Epub 2020 Oct 2. PMID: 33011728; PMCID: PMC7573895.

74. Levine BC. Autophagy Modulators as Novel Broad-Spectrum Anti-Infective Agents. https://grantome.com/grant/NIH/U19-Al142784-01.

75. Münz C. Beclin-1 targeting for viral immune escape. Viruses. 2011 Jul;3(7):1166-78. doi: 10.3390/v3071166. Epub 2011 Jul 12. PMID: 21994775; PMCID: PMC3185790.

76. Sorouri M, Chang T, Jesudhasan P, Pinkham C, Elde NC, Hancks DC. Signatures of host-pathogen evolutionary conflict reveal MISTR-A conserved Mltochondrial STress Response network. PLoS Biol. 2020 Dec 28;18(12):e3001045. doi: 10.1371/journal.pbio.3001045. PMID: 33370271; PMCID: PMC7793259.

77. Quezada H, Martínez-Vázquez M, López-Jácome E, González-Pedrajo B, Andrade Á, FernándezPresas AM, Tovar-García A, García-Contreras R. Repurposed anti-cancer drugs: the future for antiinfective therapy? Expert Rev Anti Infect Ther. 2020 Jul;18(7):609-612. doi: 10.1080/14787210.2020.1752665. Epub 2020 Apr 15. PMID: 32290720.

78. Kaufmann SH. Stressproteine: Virulenzfaktoren intrazellulärer Krankheitserreger? [Stress proteins: virulence factors of intracellular disease agents?]. Immun Infekt. 1989 Aug;17(4):124-8. German. PMID: 2673993.

79. Polla BS. Heat shock proteins in host-parasite interactions. Immunol Today. 1991 Mar;12(3):A38-41. doi: 10.1016/S0167-5699(05)80011-8. PMID: 2069677.

80. Rochani AK, Singh M, Tatu U. Heat shock protein 90 inhibitors as broad spectrum anti-infectives. Curr Pharm Des. 2013;19(3):377 - 86. doi: 10.2174/138161213804143608. PMID: 22920905.

81. Li Y, Zhang T, Schwartz SJ, Sun D. New developments in Hsp90 inhibitors as anti-cancer therapeutics: mechanisms, clinical perspective and more potential. Drug Resist Updat. 2009 FebApr;12(1-2):17-27. doi: 10.1016/j.drup.2008.12.002. PMID: 19179103; PMCID: PMC2692088.

82. Ramos $\mathrm{CHI}$, Ayinde KS. Are Hsp90 inhibitors good candidates against Covid-19? Curr Protein Pept Sci. 2020 Nov 11. doi: 10.2174/1389203721666201111160925. Epub ahead of print. PMID: 33176644.

83. Montoya MC, Krysan DJ. Repurposing Estrogen Receptor Antagonists for the Treatment of Infectious Disease. mBio. 2018 Dec 18;9(6):e02272-18. doi: 10.1128/mBio.02272-18. PMID: 30563895; PMCID: PMC6299222.

84. Dolan K, Montgomery S, Buchheit B, Didone L, Wellington M, Krysan DJ. Antifungal activity of tamoxifen: in vitro and in vivo activities and mechanistic characterization. Antimicrob Agents Chemother. 2009 Aug;53(8):3337-46. doi: 10.1128/AAC.01564-08. Epub 2009 Jun 1. PMID: 19487443; PMCID: PMC2715577. 
85. Beggs WH. Anti-Candida activity of the anti-cancer drug tamoxifen. Res Commun Chem Pathol Pharmacol. 1993 Apr;80(1):125-8. PMID: 8488339.

86. Laurence J, Cooke H, Sikder SK. Effect of tamoxifen on regulation of viral replication and human immunodeficiency virus (HIV) long terminal repeat-directed transcription in cells chronically infected with HIV-1. Blood. 1990 Feb 1;75(3):696-703. PMID: 2297571.

87. Weinstock A, Gallego-Delgado J, Gomes C, Sherman J, Nikain C, Gonzalez S, Fisher E, Rodriguez A. Tamoxifen activity against Plasmodium in vitro and in mice. Malar J. 2019 Nov 27;18(1):378. doi: 10.1186/s12936-019-3012-7. PMID: 31775753; PMCID: PMC6882195.

88. Miguel DC, Yokoyama-Yasunaka JK, Uliana SR. Tamoxifen is effective in the treatment of Leishmania amazonensis infections in mice. PLoS Negl Trop Dis. 2008 Jun 11;2(6):e249. doi: 10.1371/journal.pntd.0000249. PMID: 18545685; PMCID: PMC2398787.

89. Jordan VC. New insights into the metabolism of tamoxifen and its role in the treatment and prevention of breast cancer. Steroids. 2007 Nov;72(13):829-42. doi: 10.1016/j.steroids.2007.07.009. Epub 2007 Jul 27. PMID: 17765940; PMCID: PMC2740485.

90. Butts A, Martin JA, DiDone L, Bradley EK, Mutz M, Krysan DJ. Structure-activity relationships for the antifungal activity of selective estrogen receptor antagonists related to tamoxifen. PLoS One. 2015 May 27;10(5):e0125927. doi: 10.1371/journal.pone.0125927. PMID: 26016941; PMCID: PMC4446328.

91. Wilson DW, Goodman CD, Sleebs BE, Weiss GE, de Jong NW, Angrisano F, Langer C, Baum J, Crabb $\mathrm{BS}$, Gilson PR, McFadden GI, Beeson JG. Macrolides rapidly inhibit red blood cell invasion by the human malaria parasite, Plasmodium falciparum. BMC Biol. 2015 Jul 18;13:52. doi: 10.1186/s12915-015-0162-0. PMID: 26187647; PMCID: PMC4506589.

92. Kadappu KK, Nagaraja MV, Rao PV, Shastry BA. Azithromycin as treatment for cryptosporidiosis in human immunodeficiency virus disease. J Postgrad Med. 2002 Jul-Sep;48(3):179-81. PMID: 12432190.

93. Burns AL, Sleebs BE, Siddiqui G, De Paoli AE, Anderson D, Liffner B, Harvey R, Beeson JG, Creek DJ, Goodman CD, McFadden GI, Wilson DW. Retargeting azithromycin analogues to have dual-modality antimalarial activity. BMC Biol. 2020 Sep 29;18(1):133. doi: 10.1186/s12915-020-00859-4. PMID: 32993629; PMCID: PMC7526119.

94. Hoffman PS, Sisson G, Croxen MA, Welch K, Harman WD, Cremades N, Morash MG. Antiparasitic drug nitazoxanide inhibits the pyruvate oxidoreductases of Helicobacter pylori, selected anaerobic bacteria and parasites, and Campylobacter jejuni. Antimicrob Agents Chemother. 2007 Mar;51(3):868-76. doi: 10.1128/AAC.01159-06. Epub 2006 Dec 11. PMID: 17158936; PMCID: PMC1803158.

95. Shakya A, Bhat HR, Ghosh SK. Update on Nitazoxanide: A Multifunctional Chemotherapeutic Agent. Curr Drug Discov Technol. 2018;15(3):201-213. doi: 10.2174/1570163814666170727130003. PMID: 28748751. 
96. Hickson SE, Margineantu D, Hockenbery DM, Simon JA, Geballe AP. Inhibition of vaccinia virus replication by nitazoxanide. Virology. 2018 May;518:398-405. doi: 10.1016/j.virol.2018.03.023. Epub 2018 Apr 3. PMID: 29625403; PMCID: PMC5929478.

97. Petersen T, Lee YJ, Osinusi A, Amorosa VK, Wang C, Kang M, Matining R, Zhang X, Dou D, Umbleja T, Kottilil S, Peters MG. Interferon Stimulated Gene Expression in HIV/HCV Coinfected Patients Treated with Nitazoxanide/Peginterferon-Alfa-2a and Ribavirin. AIDS Res Hum Retroviruses. 2016 Jul;32(7):660-7. doi: 10.1089/aid.2015.0236. Epub 2016 Mar 14. PMID: 26974581; PMCID: PMC4931749.

98. Jasenosky LD, Cadena C, Mire CE, Borisevich V, Haridas V, Ranjbar S, Nambu A, Bavari S, Soloveva V, Sadukhan S, Cassell GH, Geisbert TW, Hur S, Goldfeld AE. The FDA-Approved Oral Drug Nitazoxanide Amplifies Host Antiviral Responses and Inhibits Ebola Virus. iScience. 2019 Sep 27;19:1279-1290. doi: 10.1016/j.isci.2019.07.003. Epub 2019 Aug 8. PMID: 31402258; PMCID: PMC6831822.

99. Müller J, Wastling J, Sanderson S, Müller N, Hemphill A. A novel Giardia lamblia nitroreductase, GINR1, interacts with nitazoxanide and other thiazolides. Antimicrob Agents Chemother. 2007 Jun;51(6):1979-86. doi: 10.1128/AAC.01548-06. Epub 2007 Apr 16. PMID: 17438059; PMCID: PMC1891416.

100. Amsden GW. Anti-inflammatory effects of macrolides-an underappreciated benefit in the treatment of community-acquired respiratory tract infections and chronic inflammatory pulmonary conditions? J Antimicrob Chemother. 2005 Jan;55(1):10-21. doi: 10.1093/jac/dkh519. Epub 2004 Dec 8. PMID: 15590715.

101. Banjanac M, Munić Kos V, Nujić K, Vrančić M, Belamarić D, Crnković S, Hlevnjak M, Eraković Haber V. Anti-inflammatory mechanism of action of azithromycin in LPS-stimulated J774A.1 cells. Pharmacol Res. 2012 Oct;66(4):357 - 62. doi: 10.1016/j.phrs.2012.06.011. Epub 2012 Jul 3. PMID: 22766077.

102. Zimmermann P, Ziesenitz VC, Curtis N, Ritz N. The Immunomodulatory Effects of Macrolides-A Systematic Review of the Underlying Mechanisms. Front Immunol. 2018 Mar 13;9:302. doi: 10.3389/fImmu.2018.00302. PMID: 29593707; PMCID: PMC5859047.

103. Li H, Zhou Y, Fan F, Zhang Y, Li X, Yu H, Zhao L, Yi X, He G, Fujita J, Jiang D. Effect of azithromycin on patients with diffuse panbronchiolitis: retrospective study of 51 cases. Intern Med. 2011;50(16):1663-9. doi: 10.2169/internalmedicine.50.4727. Epub 2011 Aug 15. PMID: 21841323.

104. Oliver ME, Hinks TSC. Azithromycin in viral infections. Rev Med Virol. 2021 Mar;31(2):e2163. doi: 10.1002/rmv.2163. Epub 2020 Sep 23. PMID: 32969125; PMCID: PMC7536932.

105. Firth A, Prathapan P. Broad-spectrum therapeutics: A new antimicrobial class. Current Research in Pharmacology and Drug Discovery. 2021;2:100011. doi: 10.1016/j.crphar.2020.100011. Epub 2020 Dec 11. PMCID: PMC8035643.

106. Oprea TI, Overington JP. Computational and Practical Aspects of Drug Repositioning. Assay Drug Dev Technol. 2015 Jul-Aug;13(6):299-306. doi: 10.1089/adt.2015.29011.tiodrrr. PMID: 26241209; PMCID: PMC4533090. 
107. Gatti M, De Ponti F. Drug Repurposing in the COVID-19 Era: Insights from Case Studies Showing Pharmaceutical Peculiarities. Pharmaceutics. 2021 Feb 25;13(3):302. doi:

10.3390/pharmaceutics13030302. PMID: 33668969; PMCID: PMC7996547.

108. Firth A, Prathapan P. Azithromycin: The First Broad-spectrum Therapeutic. Eur J Med Chem. 2020 Dec 1;207:112739. doi: 10.1016/j.ejmech.2020.112739. Epub 2020 Aug 19. PMID: 32871342; PMCID: PMC7434625.

109. Maynard RM, Tetley TD. Bioterrorism: the lung under attack. Thorax 2004;59:188-189.

110. Waterer GW, Robertson H. Bioterrorism for the respiratory physician. Respirology. 2009 Jan;14(1):511. doi: 10.1111/j.1440-1843.2008.01446.x. PMID: 19144044.

111. Yan S, Ci X, Chen N, Chen C, Li X, Chu X, Li J, Deng X. Anti-inflammatory effects of ivermectin in mouse model of allergic asthma. Inflamm Res. 2011 Jun;60(6):589-96. doi: 10.1007/s00011-0110307-8. Epub 2011 Jan 29. PMID: 21279416.

112. Cabrita I, Benedetto R, Schreiber R, Kunzelmann K. Niclosamide repurposed for the treatment of inflammatory airway disease. JCI Insight. 2019 Aug 8;4(15):e128414. doi:

10.1172/jci.insight.128414. PMID: 31391337; PMCID: PMC6693830.

113. Danielsson J, Perez-Zoghbi J, Bernstein K, Barajas MB, Zhang Y, Kumar S, Sharma PK, Gallos G, Emala CW. Antagonists of the TMEM16A calcium-activated chloride channel modulate airway smooth muscle tone and intracellular calcium. Anesthesiology. 2015 Sep;123(3):569-81. doi: 10.1097/ALN.0000000000000769. PMID: 26181339; PMCID: PMC4543527.

114. Miner K, Labitzke K, Liu B, Wang P, Henckels K, Gaida K, Elliott R, Chen JJ, Liu L, Leith A, Trueblood E, Hensley K, Xia XZ, Homann O, Bennett B, Fiorino M, Whoriskey J, Yu G, Escobar S, Wong M, Born TL, Budelsky A, Comeau M, Smith D, Phillips J, Johnston JA, McGivern JG, Weikl K, Powers D, Kunzelmann K, Mohn D, Hochheimer A, Sullivan JK. Drug Repurposing: The Anthelmintics Niclosamide and Nitazoxanide Are Potent TMEM16A Antagonists That Fully Bronchodilate Airways. Front Pharmacol. 2019 Feb 14;10:51. doi: 10.3389/fphar.2019.00051. PMID: 30837866; PMCID: PMC6382696.

115. Hayden EC. Biodefence since 9/11: The price of protection. Nature. 2011 Sep 7;477(7363):150-2. doi: 10.1038/477150a. PMID: 21900990.

116. Hayden EC. Pentagon rethinks bioterror effort. Nature. 2011 Sep 21;477(7365):380-1. doi: 10.1038/477380a. PMID: 21938042.

117. Fauci AS. Bioterrorism: defining a research agenda. Food Drug Law J. 2002;57(3):413-21. PMID: 12703508.

118. Kshirsagar NA, Gogtay NJ, Moran D, Utz G, Sethia A, Sarkar S, Vandenbroucke P. Treatment of adults with acute uncomplicated malaria with azithromycin and chloroquine in India, Colombia, and Suriname. Res Rep Trop Med. 2017 Oct 13;8:85-104. doi: 10.2147/RRTM.S129741. PMID: 30050349; PMCID: PMC6038897.

119. Doan T, Hinterwirth A, Arzika AM, et al. Reduction of coronavirus burden with mass azithromycin distribution. Clin Infect Dis. 2020; 
ciaa606

. doi:10.1093/cid/ciaa606. Online ahead of print.

120. Kawamura K, Ichikado K, Takaki M, Eguchi Y, Anan K, Suga M. Adjunctive therapy with azithromycin for moderate and severe acute respiratory distress syndrome: a retrospective, propensity scorematching analysis of prospectively collected data at a single center. Int J Antimicrob Agents. 2018;51(6):918-924.

121. Lee N, Wong CK, Chan MCW, et al. Anti-inflammatory effects of adjunctive macrolide treatment in adults hospitalized with influenza: a randomized controlled trial. Antiviral Res. 2017;144:48-56.

122. Ashraf, S., Chaudhry, U., Raza, A. et al. In vitro activity of ivermectin against Staphylococcus aureus clinical isolates. Antimicrob Resist Infect Control 7, 27 (2018). https://doi.org/10.1186/s13756-0180314-4

123. Rajter JC, Sherman MS, Fatteh N, Vogel F, Sacks J, Rajter JJ. Use of Ivermectin Is Associated With Lower Mortality in Hospitalized Patients With Coronavirus Disease 2019: The Ivermectin in COVID Nineteen Study. Chest. 2021 Jan;159(1):85-92. doi: 10.1016/j.chest.2020.10.009. Epub 2020 Oct 13. PMID: 33065103; PMCID: PMC7550891.

124. Lv C, Liu W, Wang B, Dang R, Qiu L, Ren J, Yan C, Yang Z, Wang X. Ivermectin inhibits DNA polymerase UL42 of pseudorabies virus entrance into the nucleus and proliferation of the virus in vitro and vivo. Antiviral Res. 2018 Nov;159:55-62. doi: 10.1016/j.antiviral.2018.09.010. Epub 2018 Sep 26. PMID: 30266338.

125. Rajamuthiah R, Fuchs BB, Conery AL, Kim W, Jayamani E, Kwon B, Ausubel FM, Mylonakis E. Repurposing salicylanilide anthelmintic drugs to combat drug resistant Staphylococcus aureus. PLoS One. 2015 Apr 21;10(4):e0124595. doi: 10.1371/journal.pone.0124595. PMID: 25897961; PMCID: PMC4405337.

126. Imperi F, Massai F, Ramachandran Pillai C, Longo F, Zennaro E, Rampioni G, Visca P, Leoni L. New life for an old drug: the anthelmintic drug niclosamide inhibits Pseudomonas aeruginosa quorum sensing. Antimicrob Agents Chemother. 2013 Feb;57(2):996-1005. doi: 10.1128/AAC.01952-12. Epub 2012 Dec 17. PMID: 23254430; PMCID: PMC3553739.

127. Tam J, Hamza T, Ma B, Chen K, Beilhartz GL, Ravel J, Feng H, Melnyk RA. Host-targeted niclosamide inhibits $\mathrm{C}$. difficile virulence and prevents disease in mice without disrupting the gut microbiota. Nat Commun. 2018 Dec 7;9(1):5233. doi: 10.1038/s41467-018-07705-w. PMID: 30531960; PMCID: PMC6286312.

128. Kao JC, HuangFu WC, Tsai TT, Ho MR, Jhan MK, Shen TJ, Tseng PC, Wang YT, Lin CF. The antiparasitic drug niclosamide inhibits dengue virus infection by interfering with endosomal acidification independent of mTOR. PLoS Negl Trop Dis. 2018 Aug 20;12(8):e0006715. doi: 10.1371/journal.pntd.0006715. PMID: 30125275; PMCID: PMC6117097.

129. Musher DM, Logan N, Hamill RJ, Dupont HL, Lentnek A, Gupta A, Rossignol JF. Nitazoxanide for the treatment of Clostridium difficile colitis. Clin Infect Dis. 2006 Aug 15;43(4):421-7. doi: 10.1086/506351. Epub 2006 Jul 11. PMID: 16838229. 
130. Musher DM, Logan N, Bressler AM, Johnson DP, Rossignol JF. Nitazoxanide versus vancomycin in Clostridium difficile infection: a randomized, double-blind study. Clin Infect Dis. 2009 Feb 15;48(4):e41-6. doi: 10.1086/596552. PMID: 19133801.

131. Haffizulla J, Hartman A, Hoppers M, Resnick H, Samudrala S, Ginocchio C, Bardin M, Rossignol JF; US Nitazoxanide Influenza Clinical Study Group. Effect of nitazoxanide in adults and adolescents with acute uncomplicated influenza: a double-blind, randomised, placebo-controlled, phase $2 \mathrm{~b} / 3$ trial. Lancet Infect Dis. 2014 Jul;14(7):609-18. doi: 10.1016/S1473-3099(14)70717-0. Epub 2014 May 19. PMID: 24852376; PMCID: PMC7164783.

\section{Figures}

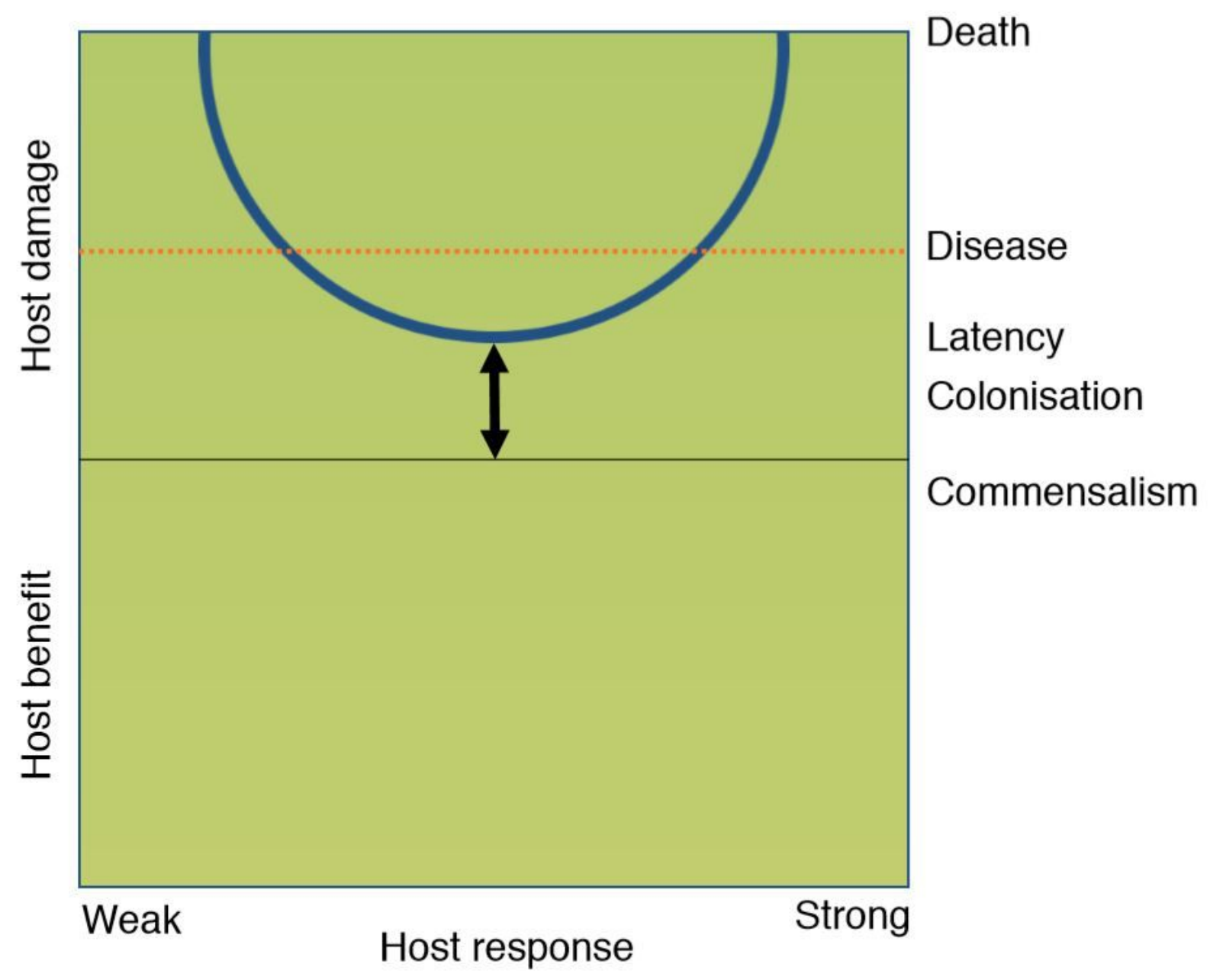

Figure 1

Casadevall and Pirofski's damage-response framework of microbial pathogenesis. The y-axis denotes host damage as a function of the host response. Damage can occur throughout the host response, which 
is represented by a continuum from 'weak' to 'strong'. Therapeutic intervention can shift the curve towards benefiting the host, as denoted by the arrow.

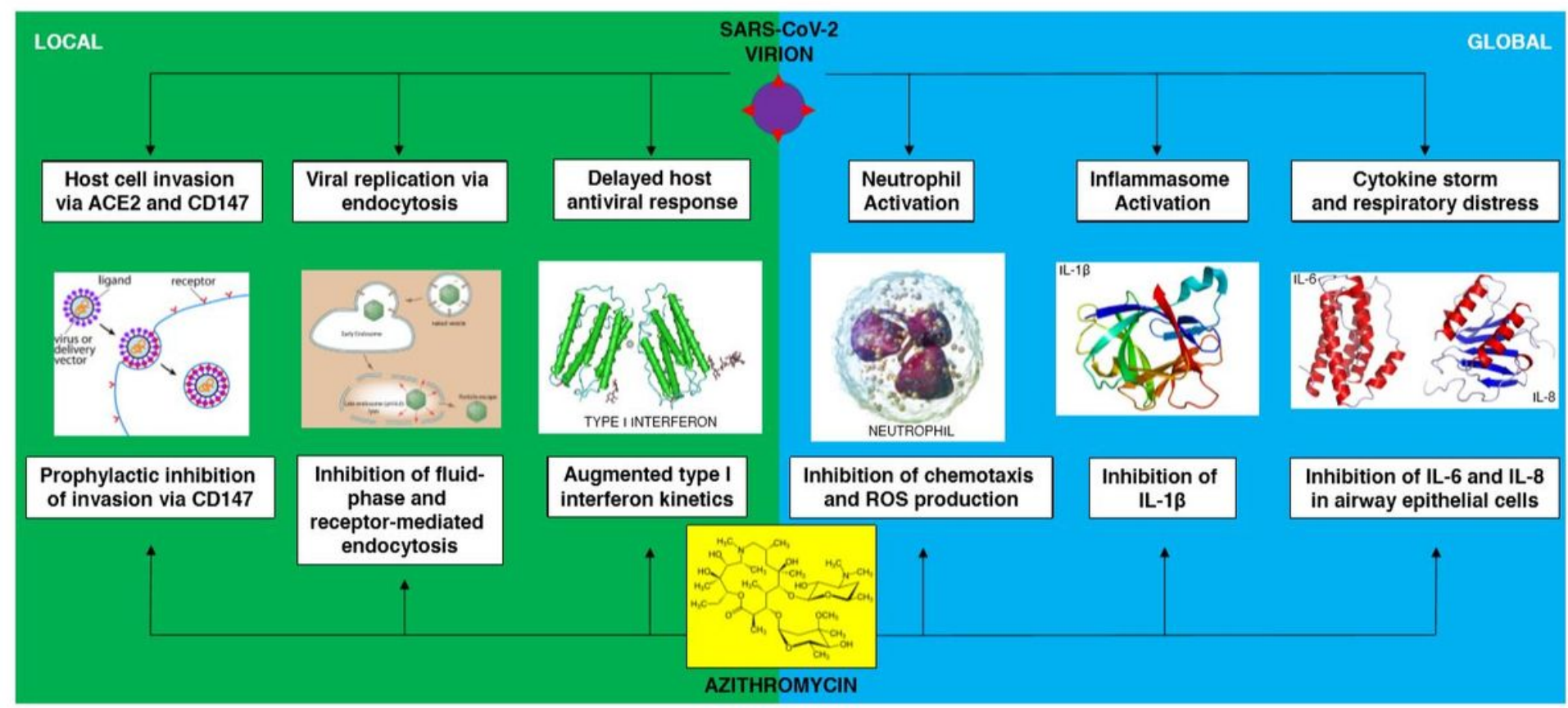

infection

COVID-19 Disease Progression

acute pneumonia

\section{Figure 2}

Pharmacological profile of azithromycin during COVID-19 pneumonia pathogenesis. Establishment of pan-pathogen antimicrobials facilitates discovery of conserved pharmacological properties against multiple pathogen types. For example, lysosomotropicity has emerged as a desideratum for both antimalarial and antiviral therapeutics. Drug-disease interactions of pan-pathogen antimicrobials can further provide mechanistic insights into the general nature of infection. In so doing, pan-pathogen antimicrobials can drive the unification of the microbiological and immunological disciplines, first envisioned by Casadevall and Pirofski. 